\title{
Enhanced Bottom-of-the-Atmosphere Cooling and Atmosphere Heating Efficiency by Mixed-Type Aerosols: A Classification Based on Aerosol Nonsphericity
}

\author{
Pengfei Tian, Lei Zhang, Xianjie Cao, Naixiu Sun, Xinyue Mo, Jiening Liang, \\ Xuetao Li, Xingai GaO, AND Beidou Zhang \\ Key Laboratory for Semi-Arid Climate Change of the Ministry of Education, \\ College of Atmospheric Sciences, Lanzhou University, Lanzhou, China
}

HONGBIN WANG

Key Laboratory of Transportation Meteorology of the China Meteorological Administration, Jiangsu Institute of Meteorological Sciences, Nanjing, China

(Manuscript received 18 January 2017, in final form 2 October 2017)

\begin{abstract}
The current understanding of the climate effects of mixed-type aerosols is an open question. The optical and radiative properties of the anthropogenic, mixed-type, and dust aerosols were studied using simultaneous observations of a sun photometer and a depolarization lidar over the Semi-Arid Climate and Environment Observatory of Lanzhou University (SACOL), northwestern China. The aerosol radiative effect was calculated using the Santa Barbara DISORT Atmospheric Radiative Transfer (SBDART) model and was in good agreement with the Aerosol Robotic Network (AERONET) product. The anthropogenic, mixed-type, and dust aerosols were identified mainly based on the lidar-measured depolarization ratio, which was supported by the airmass back trajectories. The mixed-type aerosols exhibit lower (higher) extinctions below (above) $1.5 \mathrm{~km}$ above the ground, indicating anthropogenic pollution from the atmospheric boundary layer and dust aerosols above. The dust aerosols exhibit the highest absolute radiative effect because of the highest aerosol loading. However, the mixed-type aerosols are effective in both scattering and absorbing solar radiation, leading to the highest cooling efficiency at the bottom of the atmosphere (BOA), $7.4 \%$ and $6.5 \%$ higher than those of the anthropogenic and dust aerosols, respectively. The mixed-type aerosols exhibit the highest warming efficiency in the atmosphere (ATM), 20.8\% and 28.2\% higher than the anthropogenic and dust aerosols, respectively. The mixed-type aerosols also show the lowest cooling efficiency at the top of the atmosphere (TOA). The results suggest the necessity of carefully characterizing the mixed-type aerosols in atmospheric numerical models to more precisely assess the energy budget of the Earth-atmosphere system.
\end{abstract}

\section{Introduction}

Natural and anthropogenic aerosols play an important role in the energy budget of the Earth-atmosphere system by directly interacting with atmospheric radiation through scattering and absorption (Jacobson 2001; Bond et al. 2013; Myhre et al. 2013; Kok et al. 2017) and indirectly interacting with clouds by acting as cloud condensation nuclei (CCN) or ice nuclei (IN; Twomey 1977; Li et al. 2011; Rosenfeld et al. 2014). However, it is difficult to represent aerosols and clouds in atmospheric numerical models because of a limited understanding of the aerosol direct and indirect effects (Ghan et al. 2012; Myhre et al. 2013), leading to the largest uncertainty in the estimation

\footnotetext{
Corresponding author: Dr. Lei Zhang, zhanglei@lzu.edu.cn
}

of the Earth-atmosphere system energy budget (Loeb and Su 2010; Boucher et al. 2013; Stevens 2015).

Researchers have attempted to study the optical properties of desert dust, biomass-burning, urban industrial, sea salt, and mixed-type aerosols (Dubovik et al. 2002a; Eck et al. 2010; Giles et al. 2012; Sicard et al. 2016; Tian et al. 2017). The adsorption and heterogeneous chemistry-driven mixing of atmospheric aerosols is an important process in the atmosphere (ATM; e.g., Ye et al. 2016). The mixing of aerosols of desert dust and urban pollution leads to a lower single-scattering albedo (SSA) in East Asia (Li et al. 2007; Khatri et al. 2014). The mixing of biomass-burning/black carbon (BC) aerosols with mineral dust will make the dust aerosols more absorbing in the visible and infrared wavelength range (Höller et al. 2003; Arimoto et al. 2006). Model studies 
also show that internal mixtures of aerosols yield a lower SSA (Lesins et al. 2002; Han et al. 2013; Scarnato et al. 2013). Thus, the behavior of SSA in aerosol mixing is nonlinear: instead of producing an average SSA among the aerosol types involved in the mixing process, mixed aerosols show a lower SSA than any of them.

The increase in the absorption of mixed-type aerosols has important consequences for aerosol radiative effects. García et al. (2011) have reported that the maximum radiative effect is associated with the mixture of mineral dust and biomass-burning aerosols. Case studies show that the amount of solar radiation that reaches the surface of Earth through mixtures of mineral dust and other absorbing aerosols is reduced compared to that through pure dust aerosols (Derimian et al. 2008; Obregón et al. 2015). The radiative effect and efficiency of key aerosol types have been investigated using global AERONET observations, and the results show that more absorbing aerosols are more efficient at the bottom of the atmosphere (BOA) than at the top of the atmosphere (TOA; García et al. 2012). Researchers reported that the radiative efficiency [radiative effect of unit aerosol optical depth (AOD)] of nondust aerosols is higher than that of dust aerosols at the urban Asian cities of Gwangju, South Korea (Noh et al. 2012), and Beijing, China (Yu et al. 2016). Chen et al. (2016) studied the direct radiative aerosol effect under different air quality conditions and found the maximum aerosol radiative efficiency under unpolluted conditions. Srivastava et al. (2016) investigated the possible aerosol mixing states and radiative effects in an urban region in India influenced by dust and sea salt and suggested that mixing depends on aerosol types and abundance and meteorological conditions. However, the BOA and ATM radiative efficiency enhancement of the mixedtype aerosols has not yet been statistically studied.

In the present study, the aerosol optical and radiative properties of anthropogenic, mixed-type, and dust aerosols were studied using almost 3 years of simultaneous observations from a depolarization lidar and a sun photometer over an Aerosol Robotic Network (AERONET) site in Lanzhou, China. The observation site, aerosol data, and radiative calculations are introduced in section 2 , and the aerosol classification is discussed in section 3. The optical and radiative properties of anthropogenic, mixedtype, and dust aerosols are analyzed and discussed in section 4. Finally, the conclusions are summarized in section 5 .

\section{Data and methodology}

Simultaneous observations from a National Institute for Environmental Studies (NIES) depolarization lidar and a Cimel sun- and sky-scanning radiometer (sun photometer) were recorded at the Semi-Arid Climate and Environment Observatory of Lanzhou University (SACOL; $35.946^{\circ} \mathrm{N}, 104.137^{\circ} \mathrm{E}$, and $\left.1965.8 \mathrm{~m} \mathrm{MSL}\right)$, an international research observatory (Huang et al. 2008a), from October 2009 to August 2012. The aerosol optical and radiative properties have been widely studied at SACOL using lidar and sun photometer observations (Zhang et al. 2010; Cao et al. 2013; Tian et al. 2015).

\section{a. Lidar data and processing}

The NIES depolarization lidar employs a neodymiumdoped yttrium-aluminum-garnet (Nd:YAG) laser and a receiver telescope with a diameter of $20 \mathrm{~cm}$. The linear polarization is detected at a wavelength of $532 \mathrm{~nm}$. A profile is acquired every $15 \mathrm{~min}$ with a vertical resolution of $6 \mathrm{~m}$. We previously used the NIES lidar observations to study the seasonal aerosol nonsphericity (Tian et al. 2015) and to validate the seasonal CALIOP extinction coefficient profiles (Tian et al. 2017) over SACOL.

The lidar data were denoised with an empirical mode decomposition (EMD)-based method (Tian et al. 2014). The lidar aerosol profiles within $30 \mathrm{~min}$ from a sun photometer observation were averaged to match the sun photometer data. The volume depolarization ratio profile was averaged from $120 \mathrm{~m}$ above the ground to the aerosol-scale height (Hayasaka et al. 2007) to calculate the column-average depolarization ratio. This average method provides good data quality but ignores the elevated thin layers, which might cause uncertainties in the averaged depolarization ratio when the elevated thin layers exhibit a different physical property from the boundary layer aerosols. The aerosol extinction coefficient profiles were derived from NIES lidar profiles and the sun photometer-observed AOD using the AOD constrained Fernald (1984) method described by Huang et al. (2010).

\section{b. AERONET data}

Cimel sun- and sky-scanning spectral radiometer (or sun photometer) observations have been recorded at SACOL since June 2006. SACOL has joined the AERONET program (Holben et al. 1998). The aerosol optical and microphysical characteristics were retrieved from the sun photometer observations using the automated algorithm of Dubovik et al. (2002b, 2006). The cloud-screened, quality-assured level 2.0 AERONET data were applied in this study. The uncertainty of AERONET products is described in Dubovik et al. (2000, 2002b).

The AERONET retrievals with a solar zenith angle between $50^{\circ}$ and $80^{\circ}$ show the highest accuracy (Dubovik et al. 2000); thus, only the observations with a solar zenith 
angle between $50^{\circ}$ and $80^{\circ}$ were analyzed in this research. It is essential to consider the surface albedo (SA) with respect to the aerosol radiative effect (García et al. 2012). Thus, the observations with an SA greater than 0.5 , which refer to snow-cover surfaces over SACOL, were removed from the analysis in the present research.

The sky radiance at the wavelengths of $0.440,0.675$, 0.870 , and $1.020 \mu \mathrm{m}$ was measured by the sun photometer, and the spectral optical parameters at these four wavelength bands are available in the AERONET products. However, aerosol optical properties at the wavelength of $0.550 \mu \mathrm{m}$ are more commonly used in the literature. We employed the second-order polynomial fit method described by Eck et al. (1999) to calculate AOD at $0.550 \mu \mathrm{m}$ $\left(\mathrm{AOD}_{0.55}\right)$ using $\mathrm{AOD}$ at the wavelengths of $0.440,0.675$, 0.870 , and $1.020 \mu \mathrm{m}$. SSA at $0.550 \mu \mathrm{m}$ was linearly interpolated from those at the wavelengths of 0.440 and $0.675 \mu \mathrm{m}$.

\section{c. Radiative effect calculations}

We applied the commonly used Santa Barbara DISORT Atmospheric Radiative Transfer (SBDART) model (Ricchiazzi et al. 1998) to estimate the radiative effect and efficiency at SACOL. We used AERONET AOD, SSA, asymmetry factor, Angström exponent, solar zenith angle, surface albedo, and precipitable water vapor as input parameters of the SBDART model. The lower and upper wavelength limits are 0.25 and $4.0 \mu \mathrm{m}$. The main output parameters of the SBDART model are radiative fluxes at BOA and TOA. We choose the midlatitude summer atmospheric profile for the months from March to August and the midlatitude winter profile for the other months. We use the terminology "radiative effect" rather than "radiative forcing" because radiative forcing is defined as perturbation of radiative fluxes due to human-induced components only, while radiative effect refers to the difference between radiative fluxes in aerosol-free $\left(F_{0}\right)$ and aerosol-laden $(F)$ atmospheric conditions (Remer and Kaufman 2006):

$$
\Delta F=\left(F^{\downarrow}-F^{\uparrow}\right)-\left(F_{0}^{\downarrow}-F_{0}^{\uparrow}\right),
$$

where upward and downward arrows denote the directions of the radiative fluxes. Equation (1) was applied to calculate the direct aerosol radiative effect at the TOA and $\mathrm{BOA}, \Delta F_{\mathrm{TOA}}$ and $\Delta F_{\mathrm{BOA}}$, respectively. The radiative effect in the atmosphere was computed as follows:

$$
\Delta F_{\mathrm{ATM}}=\Delta F_{\mathrm{TOA}}-\Delta F_{\mathrm{BOA}} .
$$

To make a consistent comparison between radiative effects under different aerosol loadings, the aerosol radiative efficiency $\Delta F^{\text {eff }}$ was defined to rule out the influence of the aerosol optical depth:

$$
\Delta F^{\mathrm{eff}}=\Delta F / \mathrm{AOD}_{0.55}
$$

where $\mathrm{AOD}_{0.55}$ is the interpolated $\mathrm{AOD}$ at $0.55 \mu \mathrm{m}$ as described in section $2 \mathrm{~b}$. So the unit of radiative efficiency is watts per square meter per unit AOD, which is denoted as $\mathrm{W} \mathrm{m}^{-2} \tau^{-1}$ in the following. The aerosol radiative effect is not a linear function of AOD (e.g., Markowicz et al. 2008). Thus, the aerosol radiative efficiency for low AOT will be higher than for high AOT, even for exactly the same aerosols type. To address this issue, we set the corresponding AODs at $550 \mathrm{~nm}$ to unit as introduced by Derimian et al. (2016). The AERONET program also provides the BOA and TOA radiative effect and efficiency products; technical details can be found in the literature (e.g., García et al. 2008, 2012). The AERONET radiative products at TOA and BOA were calculated as follows:

$$
\begin{aligned}
& \Delta F_{\mathrm{TOA}}=\left(F_{0}^{\uparrow}-F^{\uparrow}\right)_{\mathrm{TOA}} \quad \text { and } \\
& \Delta F_{\mathrm{BOA}}=\left(F^{\downarrow}-F_{0}^{\downarrow}\right)_{\mathrm{BOA}} .
\end{aligned}
$$

The TOA downward flux is the same with and without aerosol presence. Thus, Eq. (5) is equivalent to Eq. (1) at TOA. However, the BOA upward flux with aerosols is different from that without aerosols. Thus, Eq. (5) is modified by SA (García et al. 2012):

$$
\Delta F_{\mathrm{BOA}}=\left(F^{\downarrow}-F_{0}^{\downarrow}\right)_{\mathrm{BOA}}(1-\mathrm{SA}),
$$

where SA is the spectral average of the surface albedo at the wavelengths of $0.440,0.675,0.870$, and $1.020 \mu \mathrm{m}$.

The SBDART calculations and the AERONET products are compared in Fig. 1. The TOA, BOA, and ATM radiative effect and efficiency from the SBDART calculations agree very well with the AERONET products. The SBDART calculations were analyzed in the present research.

\section{The aerosol classification based on nonsphericity}

Although aerosol classification has been widely studied using AERONET observations (e.g., Dubovik et al. 2002a; Gobbi et al. 2007; Mielonen et al. 2009; Lee et al. 2010; Costabile et al. 2013; Xia 2014), the understanding of the mixed-type aerosols is insufficient because of the difficulty in identifying these aerosols, which always show intermediate properties among the other single-type aerosols. We attempted to classify the AERONET aerosol observations using the aerosol nonsphericity (i.e., depolarization ratio) observed by the NIES depolarization lidar. Aerosols with a column-average depolarization ratio lower than 0.10 are dominated by spherical anthropogenic aerosols, while aerosols with a depolarization ratio higher 

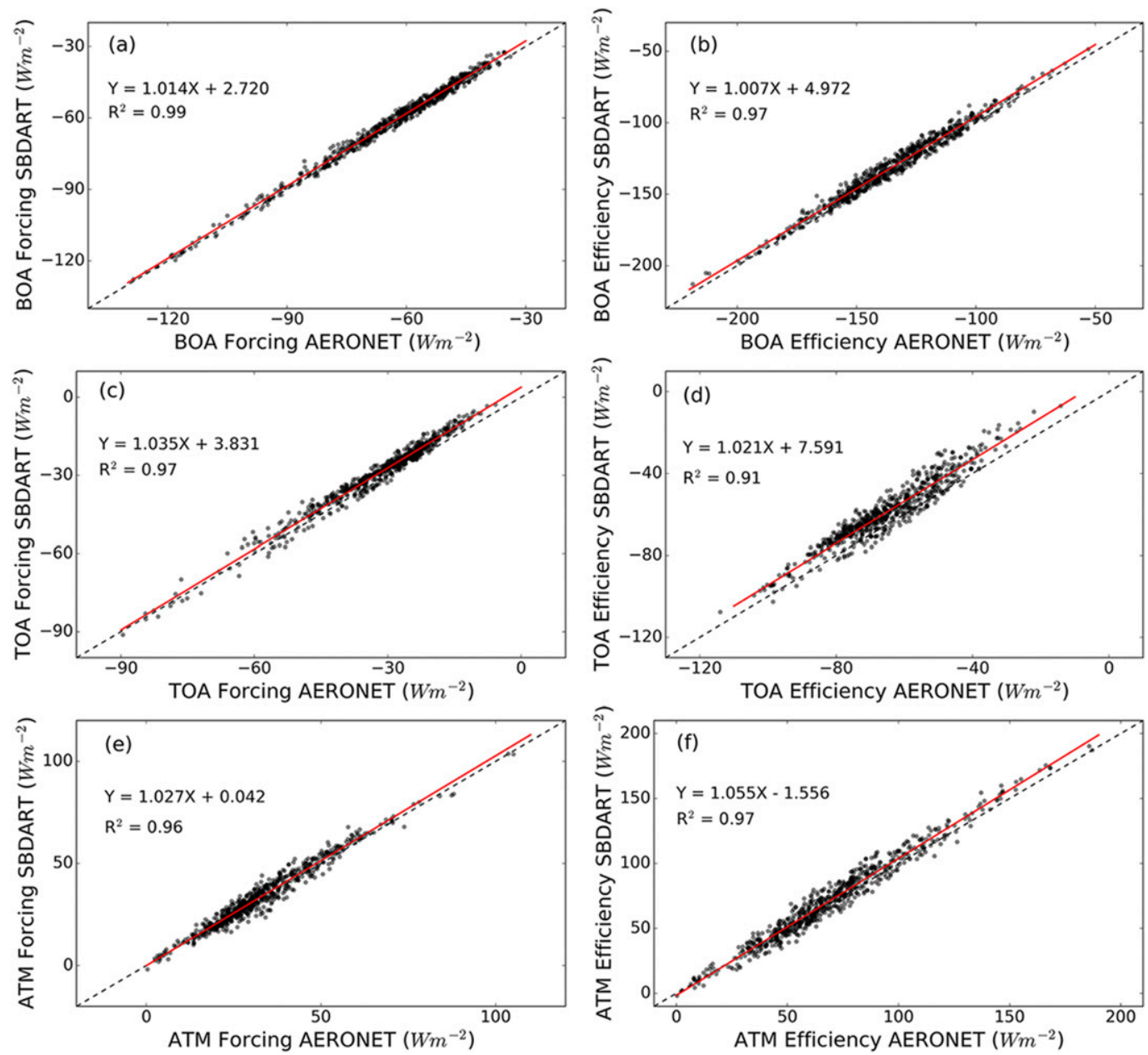

FIG. 1. Comparison of the aerosol radiative effects and efficiencies between the SBDART calculations and the AERONET products at TOA and BOA and in ATM.

than 0.20 are composed of nonspherical dust aerosols (Sugimoto et al. 2002; Heese and Wiegner 2008; Kai et al. 2008; Xie et al. 2008; Omar et al. 2009; Nemuc et al. 2013). The mixtures of anthropogenic and dust aerosols show intermediate depolarization ratio between them. Hence, aerosols with a depolarization ratio between 0.10 and 0.20 were referred to as mixed-type aerosols in the present study. Distribution of the lidar-observed column-average depolarization ratios at SACOL was plotted in Fig. 2. The column-average depolarization ratios ranged from 0.02 to 0.42 , with a peak at 0.08 . Anthropogenic aerosols (aerosols with a depolarization ratio lower than 0.10 ) accounted for $44 \%$ of the total 713 observations, while dust aerosols (aerosols with a depolarization ratio higher than 0.20) accounted for $19 \%$, and mixed-type aerosols (aerosols with a depolarization ratio between 0.10 and 0.20 ) accounted for $37 \%$ of the total observations.
We compared the aerosol nonsphericity classification results with the widely used method (Dubovik et al. 2002a; Gobbi et al. 2007; Mielonen et al. 2009) based on AERONET parameters (Fig. 3). Generally, coarse mode dust and fine mode pollution aerosols over SACOL were evident from the scatterplot of Ångström exponent versus AOD. However, identification of mixed-type aerosols from these parameters was not addressed in the literature. In addition, aerosols with a depolarization ratio between 0.10 and 0.20 vary over nearly the whole range of SSA (Fig. 3b). The lidar-observed depolarization ratio is independent of the AERONET products and thus provides a more objective way to classify the AERONET observations. This classification method was further proven by the spectral SSA result in section 4 .

To support our classification and determination of geographical origin of aerosols over SACOL, we carried 


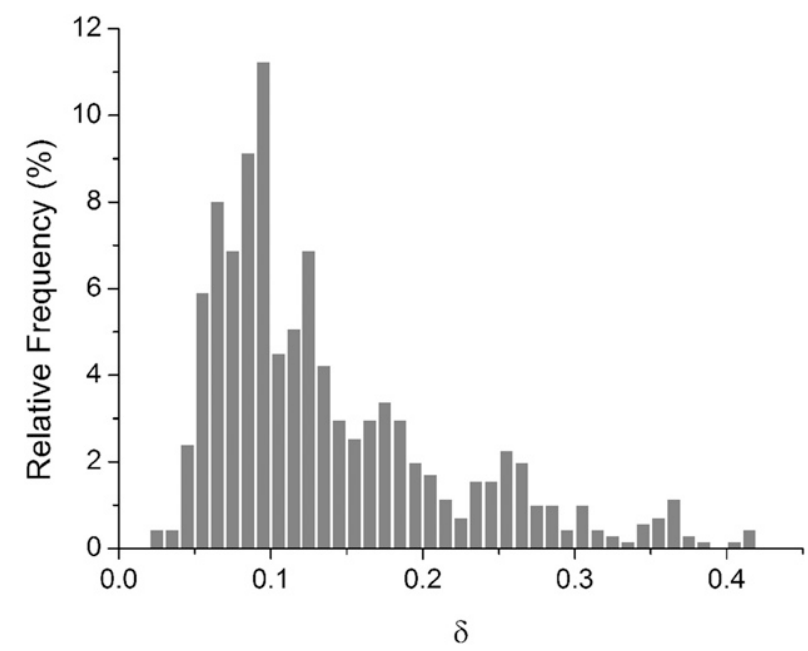

FIG. 2. Distribution of column-average depolarization ratios. The column average was calculated from $120 \mathrm{~m}$ above the ground to the aerosol scale height of every lidar profile.

out the airmass back trajectories using the National Oceanic and Atmospheric Administration (NOAA) Air Resources Laboratory (ARL)'s Hybrid Single-Particle Lagrangian Integrated Trajectory model (HYSPLIT; Draxler and Hess 1998). The ARL analysis data archive derived from the Global Data Assimilation System (GDAS) output was used as meteorological input of the HYSPLIT model. We set the starting locations at SACOL at two heights of 50 and $2000 \mathrm{~m}$. The input data are available every $3 \mathrm{~h}$, and we set the HYSPLIT model to output an airmass back trajectory every $1 \mathrm{~h}$. The nearest airmass back trajectory within 30 min was used to match the AERONET observations. As shown in Fig. 4, most of the airmass back trajectories at 2000-m height were from the west, and part of the dust conditions came from the northwest. The 24-h trajectories of the dust conditions covered a longer distance than the other conditions, indicating stronger winds under such conditions. The 50-m-height airmass back trajectories show more information about aerosol origins: the back trajectories of anthropogenic aerosols came from the northwest, southeast, and west, which covered the shortest distances; the back trajectories of the mixed-type aerosols came from the west and northwest, which covered longer distances than the anthropogenic aerosols; the back trajectories of dust aerosols mainly came from the northwest.

\section{Results and discussion}

The lidar-observed average aerosol extinction coefficient profiles for the anthropogenic, mixed-type, and dust aerosols are shown in Fig. 5. The profile of dust aerosols was much larger than that of the other two profiles, mainly because of the heavy aerosol loadings during dust events, regionally generated or long-range transported from desert dust source regions of the Taklimakan and Gobi Deserts. The average extinction profiles of anthropogenic and mixed-type aerosols were comparable but showed opposite magnitudes above and below $1.5 \mathrm{~km}$. This finding indicates regionally originated anthropogenic aerosols below $1.5 \mathrm{~km}$ and long-range transported dust aerosols above $1.5 \mathrm{~km}$. The mixed-type aerosols were a mixture of the regionally originated spherical anthropogenic aerosols and the long-range transported nonspherical desert dust aerosols over SACOL. The profile of the anthropogenic aerosols in Fig. 5 is similar to the winter-average profiles over SACOL in Cao et al. (2013) and Tian et al. (2017), whereas the profiles of the dust aerosols are larger than the spring-average profile over SACOL in Huang et al. (2008b) and Tian et al. (2017), in which the clear-sky conditions lower the average extinction coefficients.

The AERONET aerosol size distribution of the anthropogenic, mixed-type, and dust aerosols are shown in Fig. 6. The dust aerosols exhibited the highest coarse mode, whereas the anthropogenic aerosols showed the highest fine mode in the volume size distribution. The effective radius of anthropogenic, mixed-type, and

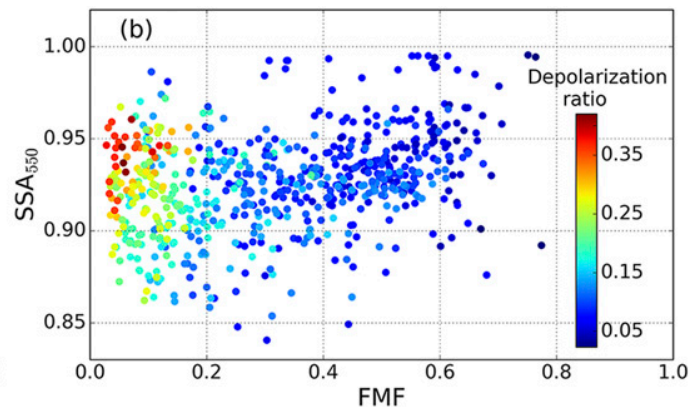

FIG. 3. Lidar-observed aerosol depolarization ratio as a function of AERONET parameters: (a) Ångström exponent and AOD and (b) SSA and fine mode fraction (FMF). 

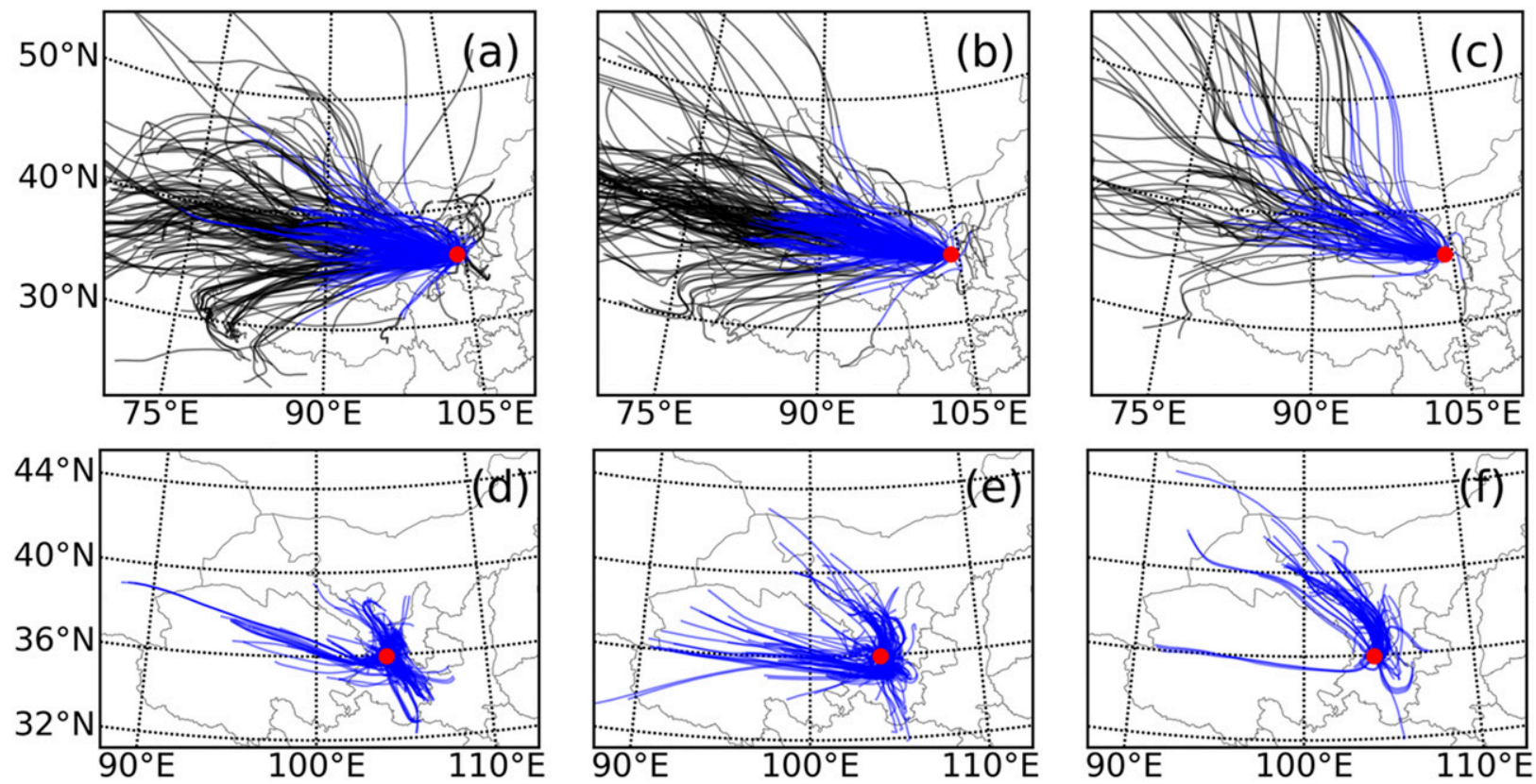

FIG. 4. Airmass back trajectories of (a),(d) anthropogenic aerosols, (b),(e) mixed-type aerosols, and (c),(f) dust aerosols started from SACOL at the heights of (a)-(c) 2000 and (d)-(f) $50 \mathrm{~m}$. The red-filled circles represent the location of SACOL. The blue lines indicate the back trajectories within $24 \mathrm{~h}$ and the black lines between 24 and $72 \mathrm{~h}$.

dust aerosols were $0.39,0.52$, and $0.85 \mu \mathrm{m}$, respectively. The effective radius of desert dust aerosols was much larger than the anthropogenic and mixed-type aerosols. It should be noted that AERONET inversion products are limited to scenarios where the 440-nm AOD is greater than 0.4 .

The spectral optical properties of the anthropogenic, mixed-type, and dust aerosols were derived from the AERONET program at the wavelengths of $0.440,0.675$, 0.870 , and $1020 \mathrm{~nm}$ (nominal wavelengths). The dust aerosols exhibited significantly higher spectral AODs than the other aerosols (Fig. 7a). The anthropogenic and the mixed-type aerosols exhibited comparable AOD values, but anthropogenic aerosols showed a stronger dependence of AOD with the wavelength. The spectral AOD was empirically expressed by Ångström (1929): the stronger the dependence between the AOD and wavelength, the higher the value of the Ångström exponent. A higher Ångström exponent is related to fine modedominated aerosols, and a lower Ångström parameter is related to coarse mode-dominated aerosols such as desert dust (Holben et al. 2001). The anthropogenic aerosols presented the strongest AOD-wavelength dependence, whereas dust aerosols presented the weakest dependence, indicating that anthropogenic aerosols are small and dust aerosols are large at SACOL, which is also evident in the aerosol volume size distribution in Fig. 6.

The spectral SSA of the dust aerosols increased with increasing wavelength, whereas that of the anthropogenic aerosols decreased slightly over SACOL (Fig. 7b). The spectral SSA of the mixed-type aerosols exhibited an increasing trend in the visible range $(0.440-0.675 \mu \mathrm{m})$, similar to that of the dust aerosols, but showed a decreasing trend in the near-infrared range $(0.870$ $1.020 \mu \mathrm{m}$ ), similar to that of the anthropogenic aerosols. It is worth noting that the mixed-type aerosols exhibited the lowest spectral SSA value. The spectral-average SSAs of anthropogenic, mixed-type, and dust aerosols were $0.935,0.925$, and 0.946 , respectively. The dust aerosols mainly originate from dust events with heavy aerosol loadings (highest AOD in Fig. 7a), leading to the highest absorption aerosol optical depth (AAOD; Fig. 7c). The spectral AAODs of the mixed-type aerosols were much higher than those of the anthropogenic aerosols (Fig. 7c) because of a stronger absorption of the mixed-type aerosols, although both types exhibited comparable AODs. Despite the fact that the dust aerosols showed the highest spectral AAOD, they are the least absorbing aerosols according to the parameters independent of aerosol loading [i.e., the highest spectral SSA (Fig. 7b) and the lowest imaginary part of the complex refractive index (Fig. 7f)].

The spectral SSA behavior has been applied to aerosol classification in previous studies. An increasing spectral trend is suggested for dust aerosols, whereas a decreasing trend is observed for urban industrial and biomassburning aerosols (e.g., Dubovik et al. 2002a; Eck et al. 2005; Giles et al. 2012). The classified anthropogenic 


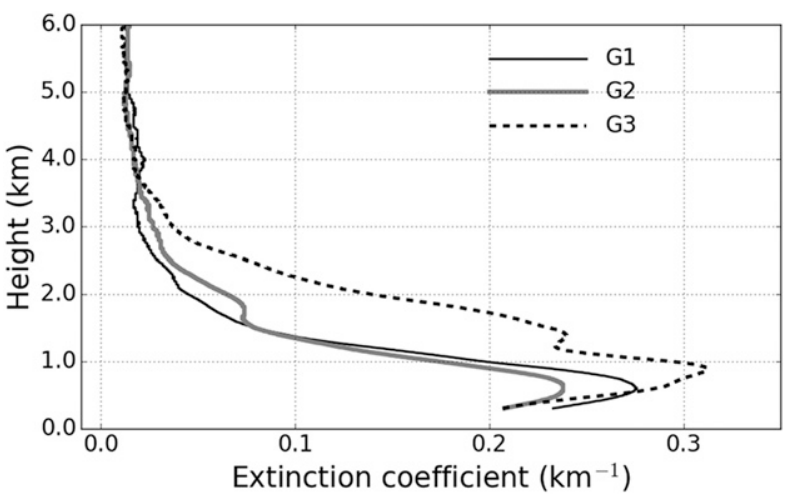

FIG. 5. Lidar-observed extinction coefficient profiles of the anthropogenic (G1), mixed-type (G2), and dust (G3) aerosols. Height is the altitude above the ground of SACOL.

aerosols in the present study mainly originate from anthropogenic sources, especially coal burning for heating in the winter, whereas the dust aerosols mainly represent transported desert dust. The spectral behavior of the SSA of the mixed-type aerosols is a compromise of the anthropogenic and the dust aerosols, but the average SSA value of the mixed-type aerosols was the lowest. The spectral SSA of the mixed-type aerosols was similar to that of the dust plume mixed with pollutants (Shin et al. 2014). Li et al. (2015) used the spectral SSA curvature to characterize mixed-type aerosols in East Asia and described a spectral behavior of the mixed-type aerosols similar to our research. The spectral behavior of the mixed-type aerosols further validates our aerosol nonsphericity-based classification method.

The asymmetry factor $g$ is a measure of the preferred scattering direction (forward or backward) for the light encountering the aerosol particles: -1.0 for only backscattering and +1.0 for only forward-scattering conditions. This parameter is mainly controlled by the aerosol size: larger aerosols exhibit more forward scattering and thus a higher asymmetry factor. The aerosol nonsphericity also alters this parameter: the nonspherical desert aerosols exhibit a slightly lower asymmetry factor than the spherical ones (e.g., Dubovik et al. 2002a; Koepke et al. 2015). In the present study, the spectral averages of the asymmetry factor of the anthropogenic, mixed-type, and dust aerosols were $0.679,0.684$, and 0.725 , respectively (Fig. $7 \mathrm{~d}$ ). The mixed-type aerosols exhibited an asymmetry factor comparable to that of the anthropogenic aerosols and showed a spectral trend similar to that of the dust aerosols.

The real part of the complex refractive index is related to the aerosol scattering ability, whereas the imaginary part of the complex refractive index indicates the absorbing ability of the aerosols. The real part of the

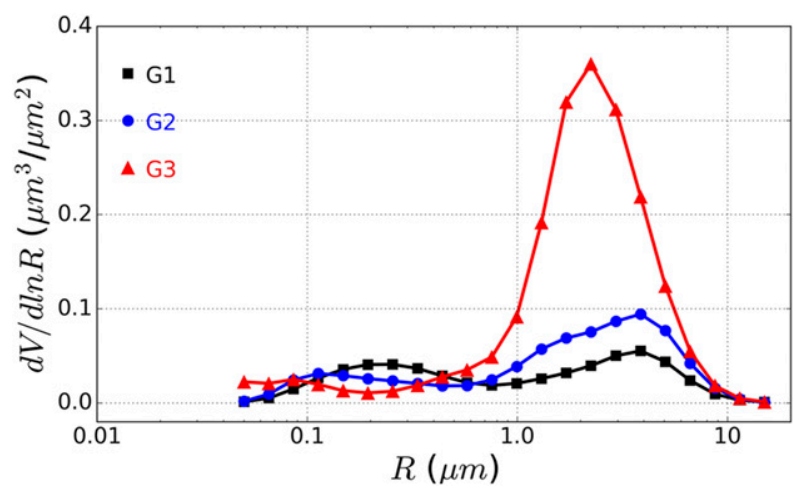

FIG. 6. AERONET-derived aerosol volume size distribution of the anthropogenic (G1), mixed-type (G2), and dust (G3) aerosols.

complex refractive index of the mixed-type aerosols was comparable to that of the dust aerosols (Figs. 7e and 7f), whereas the imaginary part of the complex refractive index of the mixed-type aerosols was close to that of the anthropogenic aerosols. Thus, the mixed-type aerosols are effective in both scattering and absorbing solar radiation over SACOL.

The BOA, TOA, and ATM aerosol radiative effects of the anthropogenic, mixed-type, and dust aerosols over SACOL were estimated using the SBDART radiative transfer model. The results are shown in Fig. 8a. To better analyze the properties of mixed-type aerosols, we included only those observations with an SSA curvature of greater than 0.1, which was suggested by Li et al. (2015) for East Asia aerosol mixtures, in radiative forcing and efficiency calculations of the mixed-type aerosols. Overall, the atmospheric aerosols cool the Earth-atmosphere system (negative TOA effect), reduce the surface solar radiation (negative BOA effect), and heat the atmosphere (positive ATM effect). The nonspherical dust aerosols exhibited the highest aerosol loadings, leading to the highest magnitudes of BOA, TOA, and ATM effects. In addition to aerosol loading, aerosol absorption plays an important role in ATM and BOA radiative effects. The magnitudes of the TOA effect of different aerosol types were thus more closely correlated with that of the average spectral AOD, whereas the magnitudes of the ATM and BOA effects of different aerosol types were more closely related to that of the average spectral AAOD.

The aerosol loading, chemical composition, and size are considered to be the most important components that control the aerosol radiative effect (Liou 2002). The nonsphericity also affects the aerosol radiative effect (Mishchenko and Hovenier 1995; Bellouin et al. 2004; Kahnert and Kylling 2004; Kahnert et al. 2005; Derimian et al. 2008; Yi et al. 2011; Koepke et al. 2015; Derimian et al. 2016). The aerosol loading is a prerequisite factor, 

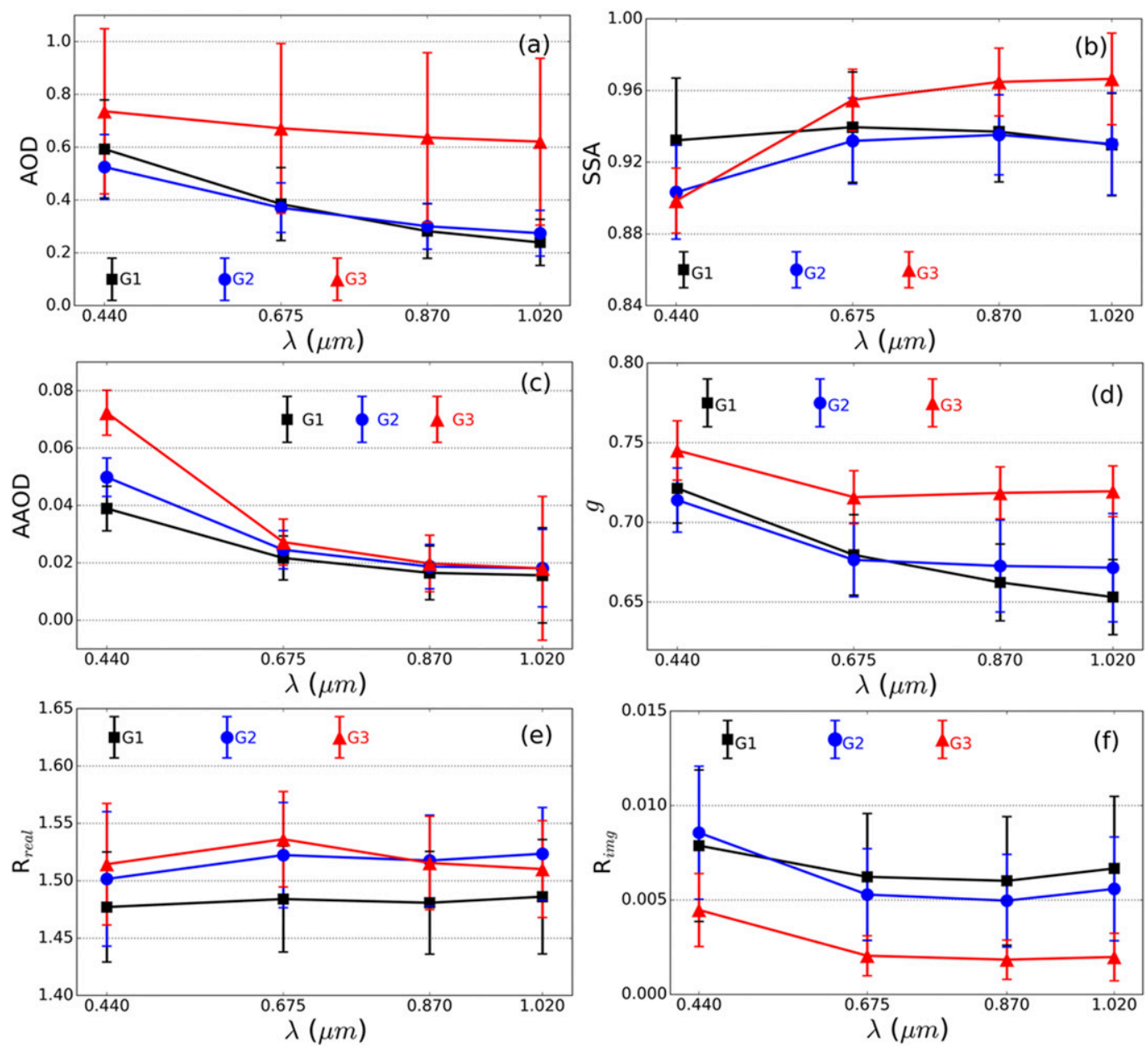

FIG. 7. The sun photometer-observed spectral (a) AOD, (b) SSA, (c) AAOD, (d) asymmetry parameter, (e) real part of the complex refractive index, and (f) imaginary part of the complex refractive index for the anthropogenic (G1), mixed-type (G2), and dust (G3) aerosols.

and the relative sizes of the aerosol radius and the incident light wavelength determine the scattering and absorption behavior of aerosols with various chemical composition. The dominant sensitivity of the aerosol radiative effect to the chemical composition is most likely to occur through the dependence of SSA (Pilinis et al. 1995; Höller et al. 2003; Huang et al. 2009; Xia et al. 2016). The BOA, TOA, and ATM radiative efficiencies of the anthropogenic, mixed-type, and dust aerosols over SACOL were calculated to rule out the effect of the aerosol loadings. The results are shown in Fig. 8b. Once the aerosol loading is ruled out, the effects of SSA and $\mathrm{g}$ are more evident.

The TOA radiative efficiencies were $-38.2 \pm$ $15.7,-32.5 \pm 8.9$, and $-42.7 \pm 12.5 \mathrm{~W} \mathrm{~m}^{-2} \tau^{-1}$ for anthropogenic, mixed-type, and dust aerosols, respectively. The dust aerosols exhibit the highest TOA cooling efficiency, and the mixed-type aerosols show the lowest TOA cooling efficiency, which is similar to the radiative efficiency results of dust and mixture of dust and biomass burning in Derimian et al. (2016).

The BOA radiative efficiencies of the anthropogenic, mixed-type, and dust aerosols were $-101.4 \pm 21.6$, $-108.9 \pm 20.8$, and $-102.3 \pm 19.4 \mathrm{~W} \mathrm{~m}^{-2} \tau^{-1}$, respectively. The mixed-type aerosols were effective in both scattering and absorbing the solar radiation (real and imaginary parts of the complex refractive index in Figs. 7e and 7f) and showed the lowest SSA, leading to the highest BOA cooling (Fig. 8b), 7.4\% and 6.5\% higher than that of the anthropogenic and dust aerosols, respectively. It is worth noting that anthropogenic and dust aerosols have comparable $\mathrm{BOA}$ radiative efficiencies. The dust aerosols are more effective in scattering, while the anthropogenic aerosols are more effective in absorption from the perspective of the complex refractive index, leading to comparable BOA 

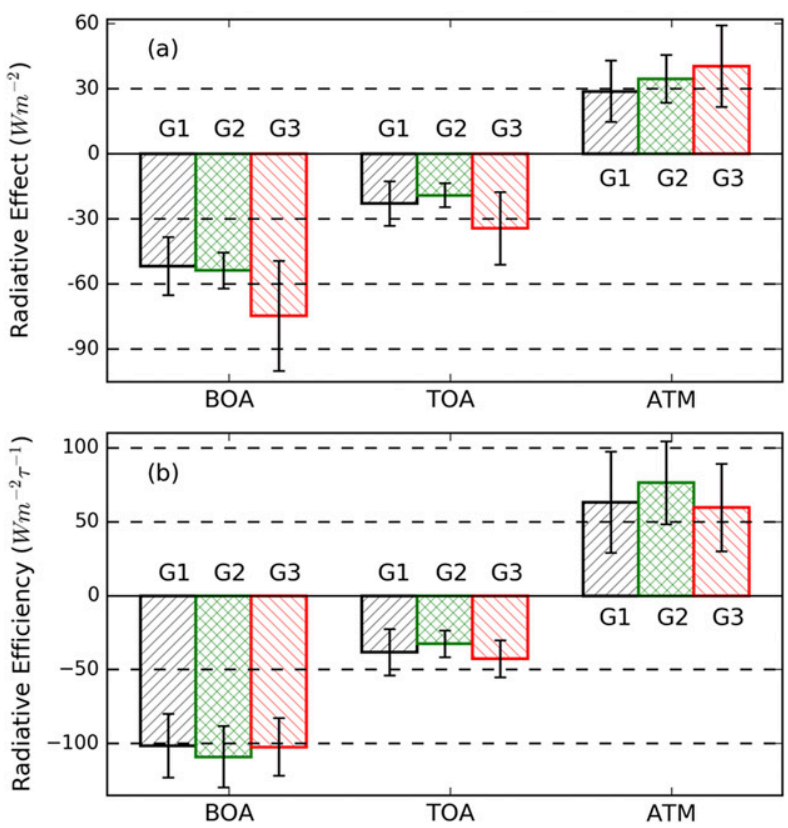

FIG. 8. The SBDART radiative transfer model-calculated (a) radiative effects and (b) radiative efficiencies of the anthropogenic (G1), mixed-type (G2), and dust (G3) aerosols.

radiative efficiencies of these two aerosol types. The BOA dust radiative efficiencies varied from -96.1 to $-127.0 \mathrm{~W} \mathrm{~m}^{-2} \tau^{-1}$ in a previous study in Beijing ( $\mathrm{Yu}$ et al. 2016), which agrees well with that of the dust aerosols $\left(-102.3 \pm 19.4 \mathrm{~W} \mathrm{~m}^{-2} \tau^{-1}\right)$ in our research. A higher BOA dust radiative cooling efficiency $(-124.6 \pm$ $12.2 \mathrm{~W} \mathrm{~m}^{-2} \tau^{-1}$ ) in Gwangju was estimated by Noh et al. (2012), in which the aerosol radiative efficiency at 1200 local time were analyzed.

Similar to BOA radiative efficiency, the mixed-type aerosols exhibit the highest ATM radiative efficiency $\left(76.4 \pm 28.0 \mathrm{~W} \mathrm{~m}^{-2} \tau^{-1}\right), 20.8 \%$ and $28.2 \%$ higher than the anthropogenic and dust aerosols $(63.2 \pm 34.2$ and $59.6 \pm 29.7 \mathrm{~W} \mathrm{~m}^{-2} \tau^{-1}$ ), respectively. Furthermore, the enhancement of the mixed-type aerosol ATM heating $(20.8 \%$ and $28.2 \%)$ was higher than that of the BOA cooling $(7.4 \%$ and $6.5 \%)$.

To test the influence of the aerosol vertical distribution on our conclusion, we used lidar extinction profiles presented in Fig. 5 as SBDART input to calculate the aerosol radiative efficiency (Table 1). The enhancements of BOA cooling and ATM heating efficiencies are also evident in Table 1. Note that we cannot set the 550-nm AOD to unit in this case because the AODs have to match lidar extinction profiles.

In fact, there were some clues indicating the radiative efficiency enhancement of the mixed-type aerosols in recent literature. For example, the Dakar site is influenced by desert dust and biomass-burning aerosols in winter,
TABLE 1. Aerosol radiative efficiency $\left(\mathrm{W} \mathrm{m}^{-2} \tau^{-1}\right)$ calculated by SBDART model using lidar-observed average extinction profile.

\begin{tabular}{lcrr}
\hline \hline & Anthropogenic & Mixed & Dust \\
\hline TOA & -45.4 & -45.0 & -48.1 \\
ATM & 76.8 & 87.9 & 73.5 \\
BOA & -122.2 & -132.9 & -121.6 \\
\hline
\end{tabular}

so the seasonal maxima of the BOA cooling and ATM heating efficiencies occur in this season (Mortier et al. 2016). Noh et al. (2012) found that the nondust days, which include conditions of the mixed-type aerosols, exhibit higher BOA cooling and ATM heating efficiencies than the dust days. Yu et al. (2016) also reported that the nondust days exhibit a higher BOA cooling efficiency than the dust days. Chen et al. (2016) concluded that unpolluted days in Beijing, which also include conditions of the mixed-type aerosols (Logan et al. 2013), show a higher BOA cooling efficiency than polluted days, when the aerosols are composed of anthropogenic aerosols (Quan et al. 2014; Zhang et al. 2015).

\section{Conclusions}

The current estimation of the aerosol radiative effect is limited by large uncertainties. Various types of aerosols are always mixed in the atmosphere, but the optical and radiative properties of the mixed-type aerosols have not been fully illustrated. We studied the optical and radiative properties of anthropogenic, mixed-type, and dust aerosols classified based on aerosol nonsphericity using almost 3 years of combined observations from a depolarization lidar and an AERONET sun photometer over SACOL.

The classified dust aerosols are mainly transported desert dust with the highest aerosol loading (highest AOD), the least absorption (highest SSA and lowest imaginary part of the complex refractive index), and the relatively highest forward scattering (highest asymmetry factor). Consequently, the dust aerosols exhibit the highest BOA cooling, TOA cooling, and ATM heating effects.

The mixed-type aerosols are effective in both scattering and absorbing the solar radiation from the perspective of the real and imaginary parts of the complex refractive index. They also exhibit the lowest SSA, with a much higher AAOD than the anthropogenic aerosols, although the AOD values for the mixed-type and the anthropogenic aerosols are comparable.

The mixed-type aerosols exhibit the highest BOA cooling efficiency $\left(-108.9 \mathrm{~W} \mathrm{~m}^{-2} \tau^{-1}\right), 7.4 \%$ and $6.5 \%$ higher than that of the anthropogenic and dust aerosols $\left(-101.4\right.$ and $\left.-102.3 \mathrm{~W} \mathrm{~m}^{-2} \tau^{-1}\right)$, respectively. 
They also exhibit the highest ATM heating efficiency $\left(+76.4 \mathrm{~W} \mathrm{~m}^{-2} \tau^{-1}\right), 20.8 \%$ and $28.2 \%$ higher than that of the anthropogenic and dust aerosols $(+63.2$ and $\left.+59.6 \mathrm{~W} \mathrm{~m}^{-2} \tau^{-1}\right)$, respectively. The TOA radiative efficiencies were $-38.2,-32.5$, and $-42.7 \mathrm{~W} \mathrm{~m}^{-2} \tau^{-1}$ for anthropogenic, mixed-type, and dust aerosols, respectively. The mixed-type aerosols show the lowest TOA cooling efficiency.

We statistically estimated the enhancement of BOA cooling and ATM heating radiative efficiencies of the mixed-type aerosols. It is necessary to carefully characterize the mixing of dust with anthropogenic aerosols in global chemical transport models to more precisely assess the aerosol BOA cooling and ATM heating effects.

Acknowledgments. This research was funded by the National Natural Science Foundation of China (41475008, 41521004, 41605005, and 41225018), the Natural Science Foundation of Jiangsu Province (BK20161073), and the Foundation of Key Laboratory for Semi-Arid Climate Change of the Ministry of Education in Lanzhou University. The authors are grateful to SACOL for providing the depolarization lidar data. We thank the AERONET program for providing aerosol products at the site of SACOL.

\section{REFERENCES}

Ångström, A., 1929: On the atmospheric transmission of sun radiation and on dust in the air. Geogr. Ann., 11, 156-166.

Arimoto, R., and Coauthors, 2006: Characterization of Asian dust during ACE-Asia. Global Planet. Change, 52, 23-56, https:// doi.org/10.1016/j.gloplacha.2006.02.013.

Bellouin, N., O. Boucher, M. Vesperini, and D. Tanré, 2004: Estimating the direct aerosol radiative perturbation: Impact of ocean surface representation and aerosol non-sphericity. Quart. J. Roy. Meteor. Soc., 130, 2217-2232, https://doi.org/ 10.1256/qj.03.136.

Bond, T. C., and Coauthors, 2013: Bounding the role of black carbon in the climate system: A scientific assessment. J. Geophys. Res. Atmos., 118, 5380-5552, https://doi.org/10.1002/jgrd.50171.

Boucher, O., and Coauthors, 2013: Clouds and aerosols. Climate Change 2013: The Physical Science Basis, T. F. Stocker et al., Eds., Cambridge University Press, 571-657.

Cao, X., Z. Wang, P. Tian, J. Wang, L. Zhang, and X. Quan, 2013: Statistics of aerosol extinction coefficient profiles and optical depth using lidar measurement over Lanzhou, China since 2005-2008. J. Quant. Spectrosc. Radiat. Transfer, 122, 150-154, https://doi.org/10.1016/j.jqsrt.2012.09.016.

Chen, W., L. Yan, N. Ding, M. Xie, M. Lu, F. Zhang, Y. Duan, and S. Zong, 2016: Analysis of aerosol radiative forcing over Beijing under different air quality conditions using ground-based sun-photometers between 2013 and 2015. Remote Sens., 8, 510, https://doi.org/10.3390/rs8060510.

Costabile, F., F. Barnaba, F. Angelini, and G. P. Gobbi, 2013: Identification of key aerosol populations through their size and composition resolved spectral scattering and absorption. Atmos. Chem. Phys., 13, 2455-2470, https://doi.org/10.5194/ acp-13-2455-2013.
Derimian, Y., and Coauthors, 2008: Radiative properties of aerosol mixture observed during the dry season 2006 over M'Bour, Senegal (African Monsoon Multidisciplinary Analysis campaign). J. Geophys. Res., 113, D00C09, https://doi.org/10.1029/ 2008JD009904.

_ , O. Dubovik, X. Huang, T. Lapyonok, P. Litvinov, A. B. Kostinski, P. Dubuisson, and F. Ducos, 2016: Comprehensive tool for calculation of radiative fluxes: Illustration of shortwave aerosol radiative effect sensitivities to the details in aerosol and underlying surface characteristics. Atmos. Chem. Phys., 16, 5763-5780, https://doi.org/10.5194/acp-16-5763-2016.

Draxler, R. R., and G. Hess, 1998: An overview of the HYSPLIT_4 modelling system for trajectories, dispersion, and deposition. Aust. Meteor. Mag., 47, 295-308.

Dubovik, O., A. Smirnov, B. N. Holben, M. D. King, Y. J. Kaufman, T. F. Eck, and I. Slutsker, 2000: Accuracy assessments of aerosol optical properties retrieved from Aerosol Robotic Network (AERONET) sun and sky radiance measurements. J. Geophys. Res., 105, 9791-9806, https://doi.org/ 10.1029/2000JD900040.

— B. N. Holben, T. F. Eck, A. Smirnov, Y. J. Kaufman, M. D. King, D. Tanré, and I. Slutsker, 2002a: Variability of absorption and optical properties of key aerosol types observed in worldwide locations. J. Atmos. Sci., 59, 590-608, https://doi. org/10.1175/1520-0469(2002)059<0590:VOAAOP > 2.0.CO;2.

,,-- T. Lapyonok, A. Sinyuk, M. I. Mishchenko, P. Yang, and I. Slutsker, 2002b: Non-spherical aerosol retrieval method employing light scattering by spheroids. Geophys. Res. Lett., 29, 1415, https://doi.org/10.1029/2001GL014506.

— count for aerosol particle nonsphericity in remote sensing of desert dust. J. Geophys. Res., 111, D11208, https://doi.org/ 10.1029/2005JD006619.

Eck, T. F., B. N. Holben, J. S. Reid, O. Dubovik, A. Smirnov, N. T. O'Neill, I. Slutsker, and S. Kinne, 1999: Wavelength dependence of the optical depth of biomass burning, urban, and desert dust aerosols. J. Geophys. Res., 104, 31333-31349, https://doi.org/10.1029/1999JD900923.

_ , and Coauthors, 2005: Columnar aerosol optical properties at AERONET sites in central eastern Asia and aerosol transport to the tropical mid-Pacific. J. Geophys. Res., 110, D06202, https://doi.org/10.1029/2004JD005274.

_ - and Coauthors, 2010: Climatological aspects of the optical properties of fine/coarse mode aerosol mixtures. J. Geophys. Res., 115, D19205, https://doi.org/10.1029/2010JD014002.

Fernald, F. G., 1984: Analysis of atmospheric lidar observations: Some comments. Appl. Opt., 23, 652-653, https://doi.org/ 10.1364/AO.23.000652.

García, O. E., and Coauthors, 2008: Validation of AERONET estimates of atmospheric solar fluxes and aerosol radiative forcing by ground-based broadband measurements. J. Geophys. Res., 113, D21207, https://doi.org/10.1029/2008JD010211.

_ - F. J. Expósito, J. P. Díaz, and A. M. Díaz, 2011: Radiative forcing under mixed aerosol conditions. J. Geophys. Res., 116, D01201, https://doi.org/10.1029/2009JD013625.

— J. P. Díaz, F. J. Expósito, A. M. Díaz, O. Dubovik, Y. Derimian, P. Dubuisson, and J. C. Roger, 2012: Shortwave radiative forcing and efficiency of key aerosol types using AERONET data. Atmos. Chem. Phys., 12, 5129-5145, https:// doi.org/10.5194/acp-12-5129-2012.

Ghan, S. J., X. Liu, R. C. Easter, R. Zaveri, P. J. Rasch, J. H. Yoon, and B. Eaton, 2012: Toward a minimal representation of aerosols in climate models: Comparative decomposition of aerosol 
direct, semidirect, and indirect radiative forcing. J. Climate, $\mathbf{2 5}$, 6461-6476, https://doi.org/10.1175/JCLI-D-11-00650.1.

Giles, D. M., and Coauthors, 2012: An analysis of AERONET aerosol absorption properties and classifications representative of aerosol source regions. J. Geophys. Res., 117, D17203, https://doi.org/10.1029/2012JD018127.

Gobbi, G. P., Y. J. Kaufman, I. Koren, and T. F. Eck, 2007: Classification of aerosol properties derived from AERONET direct sun data. Atmos. Chem. Phys., 7, 453-458, https://doi.org/ 10.5194/acp-7-453-2007.

Han, X., M. Zhang, L. Zhu, and L. Xu, 2013: Model analysis of influences of aerosol mixing state upon its optical properties in East Asia. Adv. Atmos. Sci., 30, 1201-1212, https://doi.org/ 10.1007/s00376-012-2150-4.

Hayasaka, T., S. Satake, A. Shimizu, N. Sugimoto, I. Matsui, K. Aoki, and Y. Muraji, 2007: Vertical distribution and optical properties of aerosols observed over Japan during the Atmospheric Brown Clouds-East Asia Regional Experiment 2005. J. Geophys. Res., 112, D22S35, https://doi.org/10.1029/ 2006JD008086.

Heese, B., and M. Wiegner, 2008: Vertical aerosol profiles from Raman polarization lidar observations during the dry season AMMA field campaign. J. Geophys. Res., 113, D00C11, https://doi.org/10.1029/2007JD009487.

Holben, B. N., and Coauthors, 1998: AERONET-A federated instrument network and data archive for aerosol characterization. Remote Sens. Environ., 66, 1-16, https://doi.org/ 10.1016/S0034-4257(98)00031-5.

_ , and Coauthors, 2001: An emerging ground-based aerosol climatology: Aerosol optical depth from AERONET. J. Geophys. Res., 106, 12 067-12 097, https://doi.org/10.1029/ 2001JD900014.

Höller, R., K. Ito, S. Tohno, and M. Kasahara, 2003: Wavelengthdependent aerosol single-scattering albedo: Measurements and model calculations for a coastal site near the Sea of Japan during ACE-Asia. J. Geophys. Res., 108, 8648, https://doi.org/ 10.1029/2002JD003250.

Huang, J., and Coauthors, 2008a: An overview of the Semi-Arid Climate and Environment Research Observatory over the Loess Plateau. Adv. Atmos. Sci., 25, 906-921, https://doi.org/ 10.1007/s00376-008-0906-7.

_ Z Z. Huang, J. Bi, W. Zhang, and L. Zhang, 2008b: Micro-pulse lidar measurements of aerosol vertical structure over the Loess Plateau. Atmos. Ocean. Sci. Lett., 1, 8-11.

-, Q. Fu, J. Su, Q. Tang, P. Minnis, Y. Hu, Y. Yi, and Q. Zhao, 2009: Taklimakan dust aerosol radiative heating derived from CALIPSO observations using the Fu-Liou radiation model with CERES constraints. Atmos. Chem. Phys., 9, 4011-4021, https://doi.org/10.5194/acp-9-4011-2009.

Huang, Z., and Coauthors, 2010: Dust aerosol vertical structure measurements using three MPL lidars during 2008 China-U.S. joint dust field experiment. J. Geophys. Res., 115, D00K15, https://doi.org/10.1029/2009JD013273.

Jacobson, M. Z., 2001: Strong radiative heating due to the mixing state of black carbon in atmospheric aerosols. Nature, $\mathbf{4 0 9}$, 695-697, https://doi.org/10.1038/35055518.

Kahnert, M., and A. Kylling, 2004: Radiance and flux simulations for mineral dust aerosols: Assessing the error due to using spherical or spheroidal model particles. J. Geophys. Res., 109, D09203, https://doi.org/10.1029/2003JD004318.

_ , T. Nousiainen, and B. Veihelmann, 2005: Spherical and spheroidal model particles as an error source in aerosol climate forcing and radiance computations: A case study for feldspar aerosols. J. Geophys. Res., 110, D18S13, https:// doi.org/10.1029/2004JD005558.

Kai, K., and Coauthors, 2008: The structure of the dust layer over the Taklimakan Desert during the dust storm in April 2002 as observed using a depolarization lidar. J. Meteor. Soc. Japan, 86, 1-16, https://doi.org/10.2151/jmsj.86.1.

Khatri, P., T. Takamura, A. Shimizu, and N. Sugimoto, 2014: Observation of low single scattering albedo of aerosols in the downwind of the East Asian desert and urban areas during the inflow of dust aerosols. J. Geophys. Res. Atmos., 119, 787-802, https://doi.org/10.1002/2013JD019961.

Koepke, P., J. Gasteiger, and M. Hess, 2015: Technical note: Optical properties of desert aerosol with non-spherical mineral particles: Data incorporated to OPAC. Atmos. Chem. Phys., 15, 5947-5956, https://doi.org/10.5194/acp-15-5947-2015.

Kok, J. F., and Coauthors, 2017: Smaller desert dust cooling effect estimated from analysis of dust size and abundance. Nat. Geosci., 10, 274-278, https://doi.org/10.1038/ngeo2912.

Lee, J., J. Kim, C. H. Song, S. B. Kim, Y. Chun, B. J. Sohn, and B. N. Holben, 2010: Characteristics of aerosol types from AERONET sunphotometer measurements. Atmos. Environ., 44, 3110-3117, https://doi.org/10.1016/j.atmosenv.2010.05.035.

Lesins, G., P. Chylek, and U. Lohmann, 2002: A study of internal and external mixing scenarios and its effect on aerosol optical properties and direct radiative forcing. J. Geophys. Res., 107, 4094, https://doi.org/10.1029/2001JD000973.

Li, J., B. E. Carlson, and A. A. Lacis, 2015: Using single-scattering albedo spectral curvature to characterize East Asian aerosol mixtures. J. Geophys. Res. Atmos., 120, 2037-2052, https:// doi.org/10.1002/2014JD022433.

Li, Z., and Coauthors, 2007: Preface to special section on East Asian Studies of Tropospheric Aerosols: An International Regional Experiment (EAST-AIRE). J. Geophys. Res., 112, D22S00, https://doi.org/10.1029/2007JD008853.

, F. Niu, J. Fan, Y. Liu, D. Rosenfeld, and Y. Ding, 2011: Longterm impacts of aerosols on the vertical development of clouds and precipitation. Nat. Geosci., 4, 888-894, https://doi.org/ 10.1038/ngeo1313.

Liou, K.-N., 2002: An Introduction to Atmospheric Radiation. Academic Press, 583 pp.

Loeb, N. G., and W. Su, 2010: Direct aerosol radiative forcing uncertainty based on a radiative perturbation analysis. J. Climate, 23, 5288-5293, https://doi.org/10.1175/2010JCLI3543.1.

Logan, T., B. Xi, X. Dong, Z. Li, and M. Cribb, 2013: Classification and investigation of Asian aerosol absorptive properties. Atmos. Chem. Phys., 13, 2253-2265, https://doi.org/10.5194/ acp-13-2253-2013.

Markowicz, K. M., P. J. Flatau, J. Remiszewska, M. Witek, E. A. Reid, J. S. Reid, A. Bucholtz, and B. Holben, 2008: Observations and modeling of the surface aerosol radiative forcing during $\mathrm{UAE}^{2}$. J. Atmos. Sci., 65, 2877-2891, https://doi.org/ 10.1175/2007JAS2555.1.

Mielonen, T., A. Arola, M. Komppula, J. Kukkonen, J. Koskinen, G. de Leeuw, and K. E. J. Lehtinen, 2009: Comparison of CALIOP level 2 aerosol subtypes to aerosol types derived from AERONET inversion data. Geophys. Res. Lett., 36, L18804, https://doi.org/10.1029/2009GL039609.

Mishchenko, M. I., and J. W. Hovenier, 1995: Depolarization of light backscattered by randomly oriented nonspherical particles. Opt. Lett., 20, 1356-1359, https://doi.org/10.1364/ OL.20.001356.

Mortier, A., and Coauthors, 2016: Climatology of aerosol properties and clear-sky shortwave radiative effects using lidar and sun 
photometer observations in the Dakar site. J. Geophys. Res. Atmos., 121, 6489-6510, https://doi.org/10.1002/2015JD024588.

Myhre, G., and Coauthors, 2013: Anthropogenic and natural radiative forcing. Climate Change 2013: The Physical Science Basis, T. F. Stocker et al., Eds., Cambridge University Press, 659-740.

Nemuc, A., J. Vasilescu, C. Talianu, L. Belegante, and D. Nicolae, 2013: Assessment of aerosol's mass concentrations from measured linear particle depolarization ratio (vertically resolved) and simulations. Atmos. Meas. Tech., 6, 3243-3255, https://doi.org/10.5194/amt-6-3243-2013.

Noh, Y. M., D. Müller, H. Lee, K. Lee, K. Kim, S. Shin, and Y. J. Kim, 2012: Estimation of radiative forcing by the dust and nondust content in mixed East Asian pollution plumes on the basis of depolarization ratios measured with lidar. Atmos. Environ., 61, 221-231, https://doi.org/10.1016/j.atmosenv.2012.07.034.

Obregón, M. A., S. Pereira, V. Salgueiro, M. J. Costa, A. M. Silva, A. Serrano, and D. Bortoli, 2015: Aerosol radiative effects during two desert dust events in August 2012 over the southwestern Iberian Peninsula. Atmos. Res., 153, 404-415, https:// doi.org/10.1016/j.atmosres.2014.10.007.

Omar, A. H., and Coauthors, 2009: The CALIPSO automated aerosol classification and lidar ratio selection algorithm. J. Atmos. Oceanic Technol., 26, 1994-2014, https://doi.org/ 10.1175/2009JTECHA1231.1.

Pilinis, C., S. N. Pandis, and J. H. Seinfeld, 1995: Sensitivity of direct climate forcing by atmospheric aerosols to aerosol size and composition. J. Geophys. Res., 100, 18 739-18 754, https:// doi.org/10.1029/95JD02119.

Quan, J., X. Tie, Q. Zhang, Q. Liu, X. Li, Y. Gao, and D. Zhao, 2014: Characteristics of heavy aerosol pollution during the 2012-2013 winter in Beijing, China. Atmos. Environ., 88, 83-89, https://doi.org/10.1016/j.atmosenv.2014.01.058.

Remer, L. A., and Y. J. Kaufman, 2006: Aerosol direct radiative effect at the top of the atmosphere over cloud free ocean derived from four years of MODIS data. Atmos. Chem. Phys., 6, 237-253, https://doi.org/10.5194/acp-6-237-2006.

Ricchiazzi, P., S. R. Yang, C. Gautier, and D. Sowle, 1998: SBDART: A research and teaching software tool for planeparallel radiative transfer in the Earth's atmosphere. Bull. Amer. Meteor. Soc., 79, 2101-2114, https://doi.org/10.1175/ 1520-0477(1998)079<2101:SARATS > 2.0.CO;2.

Rosenfeld, D., S. Sherwood, R. Wood, and L. Donner, 2014: Climate effects of aerosol-cloud interactions. Science, $\mathbf{3 4 3}$, 379-380, https://doi.org/10.1126/science.1247490.

Scarnato, B. V., S. Vahidinia, D. T. Richard, and T. W. Kirchstetter, 2013: Effects of internal mixing and aggregate morphology on optical properties of black carbon using a discrete dipole approximation model. Atmos. Chem. Phys., 13, 5089-5101, https://doi.org/10.5194/acp-13-5089-2013.

Shin, S., Y. M. Noh, K. Lee, H. Lee, D. Müller, Y. J. Kim, K. Kim, and D. Shin, 2014: Retrieval of the single scattering albedo of Asian dust mixed with pollutants using lidar observations. Adv. Atmos. Sci., 31, 1417-1426, https://doi.org/10.1007/ s00376-014-3244-y.

Sicard, M., R. Barragan, F. Dulac, L. Alados-Arboledas, and M. Mallet, 2016: Aerosol optical, microphysical and radiative properties at regional background insular sites in the western Mediterranean. Atmos. Chem. Phys., 16, 12177-12 203, https://doi.org/10.5194/acp-16-12177-2016.
Srivastava, R., S. Ramachandran, and T. A. Rajesh, 2016: Aerosol mixing over an urban region: Radiative effects. Quart. J. Roy. Meteor. Soc., 142, 1732-1744, https://doi.org/10.1002/qj.2769.

Stevens, B., 2015: Rethinking the lower bound on aerosol radiative forcing. J. Climate, 28, 4794-4819, https://doi.org/10.1175/ JCLI-D-14-00656.1.

Sugimoto, N., I. Matsui, A. Shimizu, I. Uno, K. Asai, T. Endoh, and T. Nakajima, 2002: Observation of dust and anthropogenic aerosol plumes in the northwest Pacific with a two-wavelength polarization lidar on board the Research Vessel Mirai. Geophys. Res. Lett., 29, 1901, https://doi.org/10.1029/2002GL015112.

Tian, P., X. Cao, J. Liang, L. Zhang, N. Yi, L. Wang, and X. Cheng, 2014: Improved empirical mode decomposition based denoising method for lidar signals. Opt. Commun., 325, 54-59, https://doi.org/10.1016/j.optcom.2014.03.083.

, - - L. Zhang, H. Wang, J. Shi, Z. Huang, T. Zhou, and H. Liu, 2015: Observation and simulation study of atmospheric aerosol nonsphericity over the Loess Plateau in northwest China. Atmos. Environ., 117, 212-219, https://doi.org/10.1016/ j.atmosenv.2015.07.020.

_ and Coauthors, 2017: Aerosol vertical distribution and optical properties over China from long-term satellite and groundbased remote sensing. Atmos. Chem. Phys., 17, 2509-2523, https://doi.org/10.5194/acp-17-2509-2017.

Twomey, S., 1977: The influence of pollution on the shortwave albedo of clouds. J. Atmos. Sci., 34, 1149-1152, https://doi.org/ 10.1175/1520-0469(1977)034<1149:TIOPOT>2.0.CO;2.

Xia, X., 2014: A critical assessment of direct radiative effects of different aerosol types on surface global radiation and its components. J. Quant. Spectrosc. Radiat. Transfer, 149, 72-80, https://doi.org/10.1016/j.jqsrt.2014.07.020.

— sol climatology in China: Aerosol optical properties, direct radiative effect and its parameterization. Atmos. Environ., 124, 243-251, https://doi.org/10.1016/j.atmosenv.2015.05.071.

Xie, C. B., T. Nishizawa, N. Sugimoto, I. Matsui, and Z. F. Wang, 2008: Characteristics of aerosol optical properties in pollution and Asian dust episodes over Beijing, China. Appl. Opt., 47, 4945-4951, https://doi.org/10.1364/AO.47.004945.

Ye, Q., E. S. Robinson, X. Ding, P. Ye, R. C. Sullivan, and N. M. Donahue, 2016: Mixing of secondary organic aerosols versus relative humidity. Proc. Natl. Acad. Sci. USA, 113, 12 649-12 654, https://doi.org/10.1073/pnas.1604536113.

Yi, B. Q., C. N. Hsu, P. Yang, and S. C. Tsay, 2011: Radiative transfer simulation of dust-like aerosols: Uncertainties from particle shape and refractive index. J. Aerosol Sci., 42, 631-644, https://doi.org/10.1016/j.jaerosci.2011.06.008.

$\mathrm{Yu}, \mathrm{X}$., and Coauthors, 2016: Dust aerosol properties and radiative forcing observed in spring during 2001-2014 over urban Beijing, China. Environ. Sci. Pollut. Res., 23, 15 432-15 442, https://doi.org/10.1007/s11356-016-6727-9.

Zhang, L., X. Cao, J. Bao, B. Zhou, J. Huang, J. Shi, and J. Bi, 2010: A case study of dust aerosol radiative properties over Lanzhou, China. Atmos. Chem. Phys., 10, 4283-4293, https://doi.org/ 10.5194/acp-10-4283-2010.

Zhang, R. Y., and Coauthors, 2015: Formation of urban fine particulate matter. Chem. Rev., 115, 3803-3855, https://doi.org/ 10.1021/acs.chemrev.5b00067. 